\title{
Dose Econômica Ótima de AcIFluORFen + Bentazon PARA Controle de Picão-Preto e GuanXuma em Soja ${ }^{1}$
}

\author{
Optimum Economic Rate of Acifluorfen + Bentazon to Control Beggarticks and \\ Arrowleaf Sida in Soybean
}

RIZZARDI, M.A. ${ }^{2}$ e FLECK, N.G. ${ }^{3}$

\begin{abstract}
RESUMO - As doses dos herbicidas são estabelecidas para uso em uma ampla variação de condições ambientais e de manejo das culturas. Contudo, algumas vezes, as doses de herbicidas podem ser reduzidas e, ainda assim, a interferência das plantas daninhas com a cultura pode ser suprimida. O objetivo deste trabalho foi testar a redução de dose para o herbicida acifluorfen + bentazon no controle de picão-preto (Bidens spp.) e guanxuma (Sida rhombifolia), em diferentes estádios de desenvolvimento das plantas daninhas, em relação à época de emergência da soja. Para isso, foi conduzido experimento em campo, em Passo Fundo - RS, cujos tratamentos constaram de quatro doses do herbicida $\left(1,25 ; 1,5 ; 1,75\right.$; e $\left.2,0 \mathrm{~L} \mathrm{ha}^{-1}\right)$, aplicadas em cinco combinações de estádios de desenvolvimento da cultura e das plantas daninhas, além de duas testemunhas, uma sem controle das plantas daninhas e outra em que estas foram arrancadas manualmente nas mesmas datas das aplicações/herbicidas. Considerando-se todas as situações testadas, o grau de controle de guanxuma variou entre 80 e $99 \%$ e o de picão-preto entre 78 e $99 \%$. Constatou-se, para as duas espécies-alvo, que o melhor controle, considerando todo o ciclo, foi a aplicação em plantas daninhas com quatro folhas. Os resultados obtidos mostram que o incremento na dose de acifluorfen + bentazon, na faixa de 1,25 a 2,0 L ha ${ }^{-1}$, resulta em retorno linear positivo, em termos de produtividade da soja. A dose de rótulo de $2,0 \mathrm{~L} \mathrm{ha}^{-1}$ foi a que se mostrou biologicamente mais eficaz; já doses próximas a $75 \%$ da dose de rótulo foram as que compensaram, economicamente, a adoção do controle.
\end{abstract}

Palavras-chave: Bidens pilosa, Bidens sulbalternans, Sida rhombifolia, herbicidas, épocas de aplicação, perda de rendimento.

\begin{abstract}
Herbicide rates are established to be applied under a range of environment and crop management conditions. Sometimes, herbicide rates can be reduced and, yet, suppress weed interference in a crop. The aim of this study was to test rate reduction for the herbicide acifluorfen + bentazon to control beggarticks (Bidens spp.) and arrowleaf sida (Sida rhombifolia), at different weed development stages relative to soybean emergence time. A field experiment was carried out in Passo Fundo, RS, with treatments consisting of five application times and four Doble rates (1,25; 1,5; 1,75 e 2,0 L hat), plus two checks, (without weed control and with weeds removed by hand, at the same times of herbicideapplication. Considering all the situations tested, the level of arrowleaf sida control varied from 80 to $99 \%$, whereas that of beggarticks varied from 78 to 99\%. For the whole cycle evaluation of the target species, the best control was found to be application in the four-leaf plants. Increasing acifluorfen + bentazona rate in the 1.25 to $2.0 \mathrm{~L} \mathrm{ha}{ }^{1}$ range results in a positive linear soybean yield return. The most biologically efficient rate was the $2.0 \mathrm{~L} \mathrm{ha}$ labeled rate. The rates close to $75 \%$ of the labeled rate provided thebest economic return.
\end{abstract}

Key words: Bidens pilosa, Bidens sulbalternans, Sida rhombifolia, herbicides, spraying time, yield loss.

Recebido para publicação em 5.5.2003 e na forma revisada em 5.3.2004.

Eng.-Agr., Dr., Professor da Faculdade de Agronomia e Medicina Veterinária da Universidade de Passo Fundo - UPF, Caixa Postal 611, 99001-970 Passo Fundo-RS, <rizzardi@upf.tche.br>; ${ }^{3}$ Eng.-Agr., Ph.D., Professor do Departamento de Plantas de Lavoura da Faculdade de Agronomia da Universidade Federal do Rio Grande do Sul - UFRGS, Bolsista do CNPq, <fleck@ufrgs.br>. 


\section{INTRODUÇÃO}

Ao longo dos anos, foram desenvolvidos diversos herbicidas seletivos e eficazes para uso em culturas, oportunizando mudar de uma solução basicamente preventiva para uma reparadora no controle de plantas daninhas (Wilkerson et al., 1991). Herbicidas de aplicação em pós-emergência são usados com bastante sucesso no controle de plantas daninhas na cultura da soja. As aplicações foliares apresentam vantagens em relação às aplicações ao solo, pois podem ser usadas após emergência e identificação das plantas daninhas, permitindo, desse modo, que os herbicidas sejam aplicados onde houver real presença de plantas daninhas (Devlin et al., 1991). Ao se permitir a emergência prévia das plantas daninhas, pode-se então selecionar os herbicidas que sejam mais eficazes, reduzindo as aplicações desnecessárias de produtos ao solo em área total (Shaw et al., 1998).

Graus satisfatórios de controle de plantas daninhas freqüentemente são obtidos com uso de doses herbicidas abaixo daquelas normalmente recomendadas no rótulo dos produtos (Boström \& Fogelfors, 2002). As doses de rótulo usualmente são fixadas para englobar um grau de controle eficiente sobre uma ampla variação de condições ambientais e de manejo (Devlin et al., 1991). Algumas vezes, com um adequado manejo e/ou sob certas condições de ambiente, as doses dos herbicidas podem ser reduzidas e, ainda, prover controle eficiente das plantas daninhas (Devlin et al., 1991; Klingaman et al., 1992; Boström \& Fogelfors, 2002). Nesse sentido, Dieleman et al. (1996) observaram que, dependendo do nível desejado de controle, poderia ser escolhido um herbicida que eliminasse completamente as plantas daninhas (dose de rótulo ou biologicamente eficaz), ou um que apenas reduzisse o crescimento das plantas daninhas e, dessa forma, neutralizasse sua interferência na cultura (dose ótima). Ao compararem a dose de rótulo com a dose ótima, tanto Dieleman et al. (1996) quanto Bosnic \& Swanton (1997) constataram que doses economicamente ótimas eram bem inferiores às doses registradas em rótulo. Para os autores, as doses economicamente ótimas asseguram maximização do lucro e reduzem a quantidade de produtos herbicidas no ambiente.
A determinação da dose ótima de um herbicida é influenciada pela época de emergência das plantas daninhas (Dieleman et al., 1996). A inclusão da época relativa de emergência das plantas daninhas melhora a habilidade interpretativa da tomada de decisão, pois ela influencia diretamente a definição da dose ótima (Bosnic \& Swanton, 1997). Para Dieleman et al. (1996), a época de emergência de plantas de Amaranthus spp. teve papel significativo na análise econômica por meio da influência que exerceu sobre a função dano das plantas daninhas.

A definição da dose ótima não implica, necessariamente, o uso de doses reduzidas, mas a seleção da dose de herbicida mais apropriada para o controle de uma planta daninha específica num estádio de crescimento definido (Bosnic \& Swanton, 1997). Para Devlin et al. (1991), a redução nas doses de herbicidas, com a manutenção de adequado controle de plantas daninhas, resulta em aumento nos lucros do produtor e em diminuição no potencial do herbicida percolar ou lixiviar no solo. Uma alternativa óbvia para reduzir o custo do controle de plantas daninhas é diminuir o número de aplicações herbicidas e/ou as doses requeridas para alcançar um nível aceitável de controle (Defelice et al., 1989).

Considerando-se que os herbicidas de pósemergência são mais eficientes em plantas daninhas de tamanho pequeno, sua aplicação no início da estação de crescimento permite o uso de doses reduzidas destes produtos (Devlin et al., 1991). Nesse aspecto, os resultados de experimento conduzido por Klingaman et al. (1992) indicaram que a redução da dose do herbicida imazethapyr não foi eficaz sob todas as condições de aplicação. Para os autores, sua aplicação em plantas jovens foi fator crítico em permitir reduzir a dose do produto. De forma similar, aplicações dos herbicidas acifluorfen, bentazon e chlorimuron em pós-emergência, nos estádios iniciais de crescimento das plantas daninhas, quando as plantas estavam pequenas, possibilitaram o uso de doses reduzidas; o controle foi mantido equivalente ou melhor do que aquele obtido com a dose de rótulo (Devlin et al., 1991). Assim como muitos estudos indicam que herbicidas de uso em pósemergência são eficientes sobre plantas pequenas (Defelice et al., 1989; Klingaman 
et al., 1992; Johnson et al., 1998), o controle de plantas daninhas no início do desenvolvimento da soja é especialmente importante, porque seu rendimento normalmente não é afetado se as lavouras forem mantidas livres destas plantas nas primeiras três a quatro semanas após a emergência (Devlin et al., 1991).

Por outro lado, o controle de plantas daninhas mais desenvolvidas requer, normalmente, doses maiores de herbicidas (Berti et al., 1996). Por exemplo, a idade e o tamanho de plântulas de Sorghum halepense influenciaram a eficiência de herbicidas graminicidas, sendo observado controle inferior quando as plantas apresentavam mais folhas e quando as aplicações foram realizadas mais tarde, especialmente quando os graminicidas foram usados em doses reduzidas (Jordan et al., 1997).

Desse modo, o presente trabalho teve por objetivo testar a redução da dose do herbicida Doble (acifluorfen + bentazon) no controle de picão-preto (Bidens spp.) e guanxuma (Sida rhombifolia), sob variação do estádio de desenvolvimento das plantas daninhas, em relação à época de emergência da soja.

\section{MATERIAL E MÉTODOS}

O experimento foi conduzido em campo, no Centro de Extensão e Pesquisa Agropecuária (Cepagro) da Faculdade de Agronomia e Medicina Veterinária da Universidade de Passo Fundo (FAMV/UPF), no município de Passo Fundo, em solo classificado como Latossolo Vermelho Distrófico típico (Embrapa, 1999).

O experimento foi implantado utilizandose o sistema de semeadura direta, em área contendo cobertura vegetal composta por aveiapreta (Avena strigosa). O manejo da cobertura foi realizado através da aplicação dos herbicidas glyphosate $(900 \mathrm{~g}$ de equivalente ácido $\left.\mathrm{ha}^{-1}\right)+2$,4-D (670 g de equivalente ácido $\mathrm{ha}^{-1}$ ), ocorrida 10 dias antes da primeira época de semeadura da soja. Aos três dias antes da primeira semeadura da soja foi aplicado o herbicida paraquat (300 $\mathrm{g} \mathrm{ha}^{-1}$ ), a fim de eliminar plantas daninhas que emergiram após a primeira dessecação.

O delineamento experimental utilizado foi o de blocos casualizados, dispostos em parcelas subdivididas. Foram utilizadas quatro repetições. Nas parcelas principais foram alocadas as épocas de aplicação do herbicida Doble (acifluorfen + bentazon) e nas subparcelas os tratamentos de controle. Os tratamentos constaram de cinco épocas de aplicação (Tabela 1) e de quatro doses de herbicidas (Tabela 2), além de uma testemunha sem controle das plantas daninhas e de uma em que elas foram eliminadas manualmente nas datas das aplicações dos herbicidas.

O experimento foi instalado em área com infestação predominante de guanxuma (Sida rhombifolia) e de picão-preto (Bidens spp.), com populações médias de 128 e 72 plantas $\mathrm{m}^{-2}$, respectivamente. No caso de picão-preto, a infestação era composta pela mistura das espécies Bidens pilosa e Bidens sulbalternans. A infestação de espécies gramíneas existentes na área foi controlada em pós-emergência, com o herbicida clethodim (120 $\left.\mathrm{g} \mathrm{ha}^{-1}\right)$.

Tabela 1 - Representação esquemática dos tratamentos testados. Passo Fundo-RS, 1998/99

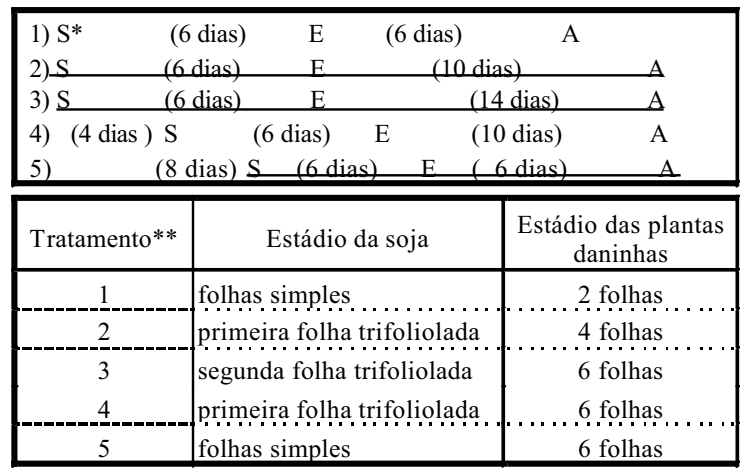

* $\mathrm{S}=$ semeadura da soja; $\mathrm{E}=$ emergência da soja; $\mathrm{A}=$ aplicação do herbicida.

** Corresponde às épocas de aplicação do herbicida.

Tabela 2 - Relação das doses dos herbicidas utilizadas no experimento. Passo Fundo-RS, 1998/99

\begin{tabular}{|c|c|c|}
\hline $\begin{array}{c}\text { Dose do herbicida } \\
(\%)\end{array}$ & $\begin{array}{c}\text { Dose herbicida* } \\
\left(\mathrm{L} \mathrm{ha}^{-1}\right)\end{array}$ & $\begin{array}{c}\text { Ingrediente ativo } \\
\left(\mathrm{g} \mathrm{ha}^{-1}\right)\end{array}$ \\
\hline 100,0 & 2,00 & $600+160$ \\
$87,5 \ldots \ldots \ldots \ldots \ldots \ldots \ldots \ldots \ldots \ldots \ldots \ldots \ldots \ldots \ldots \ldots \ldots \ldots$ & $525+140 \ldots \ldots \ldots$ \\
75,0 & 1,50 & $450+120$ \\
62,5 & 1,25 & $375+100$ \\
\hline
\end{tabular}

* Doble (bentazon $300 \mathrm{~g} \mathrm{~L}^{-1}+$ acifluorfen $80 \mathrm{~g} \mathrm{~L}^{-1}$ ), ao qual foi adicionado o adjuvante Assist na dose de $0,5 \mathrm{~L} \mathrm{ha}^{-1}$.

Planta Daninha, Viçosa-MG, v.22, n.1, p.117-125, 2004 
A adubação de manutenção, com base na análise do solo, foi realizada com a aplicação de $60 \mathrm{~kg}$ de $\mathrm{K}_{2} \mathrm{O} \mathrm{ha}^{-1}$ e $90 \mathrm{~kg}$ de $\mathrm{P}_{2} \mathrm{O}_{5} \mathrm{ha}^{-1}$. Antes da semeadura foi efetuada a inoculação das sementes de soja com estirpe específica e, após, elas foram tratadas com o fungicida thiram (70 g $100 \mathrm{~kg}^{-1}$ de sementes). A soja, cultivar Embrapa 66, foi semeada mecanicamente em espaçamento de 0,4 m entre fileiras, obtendose densidade média de 400.000 plantas haapós a emergência da cultura. As semeaduras da soja foram realizadas em 19 de novembro para os tratamentos 1 a 3 (Tabela 1), em 23 de novembro para o tratamento 4 e em 27 de novembro para o tratamento 5 . Cada subparcela esteve formada por sete fileiras de soja com $4 \mathrm{~m}$ de comprimento, totalizando uma área de $12 \mathrm{~m}^{2}$.

Nas aplicações dos herbicidas utilizou-se pulverizador costal de precisão, o qual foi operado com bicos de jato plano em leque, série 110.03 , à pressão constante de $200 \mathrm{kPa}$, com distribuição de volume de calda equivalente a $200 \mathrm{~L} \mathrm{ha}^{-1}$. Aos 7, 14 e 21 dias após aplicação (DAA) do herbicida e por ocasião da colheita, foi avaliado visualmente o controle propiciado pelos tratamentos. Para isso, utilizou-se escala percentual, em que a nota zero correspondeu a nenhum efeito de controle e a nota 100 significou morte completa das plantas.

O rendimento de grãos de soja foi estimado em área amostrada de 4,8 $\mathrm{m}^{2}$, englobando as quatro fileiras centrais das parcelas. As perdas de rendimento de grãos da cultura, para cada tratamento, foram calculadas em relação à testemunha sem a presença de plantas daninhas, sendo expressas em $\mathrm{kg} \mathrm{ha}^{-1}$ ou dólares $\mathrm{ha}^{-1}(\$)$. Foi considerada dose econômica ótima (DEO) a dose na qual a curva de perda de rendimento, em dólares ha ${ }^{-1}$, interceptou o custo de controle. Para Bosnic \& Swanton (1997), DEO é aquela dose do herbicida na qual a perda monetária de rendimento iguala-se ao custo de controle propiciado pelo uso da dose de rótulo do herbicida, acrescido do custo da aplicação. O custo do controle foi de $\$ 20,00 \mathrm{ha}^{-1}$ e representa o custo da dose de rótulo do herbicida $\left(2,0 \mathrm{~L} \mathrm{ha}^{-1}\right)$, acrescido do custo do adjuvante Assist $\left(0,5 \mathrm{~L} \mathrm{ha}^{-1}\right)$ e do custo da aplicação.

Os dados obtidos para as variáveis avaliadas foram submetidos à análise de variância pelo teste F. Quando significativos, os efeitos de épocas de aplicação do herbicida foram comparados pelo teste de Tukey a 5\% de probabilidade. Nas interações utilizou-se a probabilidade de $10 \%$. A fim de comparar os efeitos de doses, procedeu-se à análise de regressão para a respectiva variável-resposta, sendo utilizados os modelos linear e quadrático para ajustar a distribuição dos dados obtidos. Os dados percentuais relativos ao controle de papuã foram transformados por raiz quadrada de $(x+1)$, para a realização da análise de variância.

\section{RESULTADOS E DISCUSSÃO}

A semeadura da soja realizada em diferentes épocas pós-dessecação da vegetação de cobertura permitiu que se criasse um gradiente de estádios de crescimento diferenciados das plantas daninhas em relação à soja, de tal forma que nos tratamentos 1 , 2 e 3 (Tabela 1) a soja emergiu antes das plantas daninhas; já no tratamento 4 a soja emergiu junto com as plantas daninhas e, no tratamento 5, depois destas. Esse gradiente possibilitou que os tratamentos herbicidas fossem aplicados em diferentes estádios de desenvolvimento da soja e das plantas daninhas.

Em todas as situações testadas, o grau de controle de guanxuma variou entre 80 e $99 \%$ (Figuras 1 e 2). A interação da época de controle e da dose de herbicida somente foi significativa na avaliação realizada aos 7 DAA (Figura 1). Observa-se que, principalmente nas menores doses, houve maior grau de controle naqueles tratamentos em que a aplicação do herbicida foi realizada quando as plantas daninhas se apresentavam em estádios iniciais de desenvolvimento (duas a quatro folhas). Esse maior grau de controle pode estar associado à melhor eficiência do herbicida quando foi aplicado em plantas mais jovens (Dieleman et al., 1996). No entanto, essas diferenças no grau de controle em função de épocas de aplicação e de doses do herbicida não ocorreram nas demais avaliações realizadas.

Tanto para o controle de guanxuma quanto para o de picão-preto (Tabelas 3 e 4), a interação de épocas de controle e doses do herbicida não foi significativa $(P=0,27)$. $O$ controle de guanxuma, nas médias das doses do 


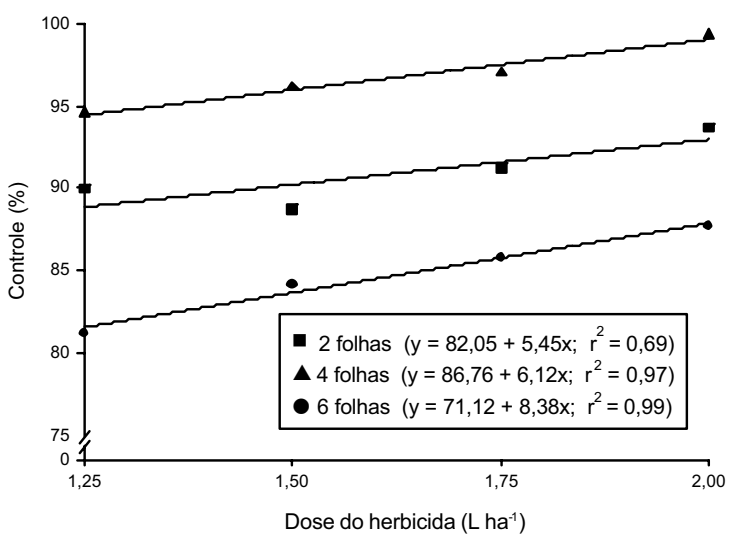

Figura 1 - Grau de controle de guanxuma (Sida rhombifolia), sete dias após aplicação do herbicida acifluorfen + bentazon, em função de doses e de estádios de desenvolvimento da planta daninha. Passo Fundo-RS, 1998/99.

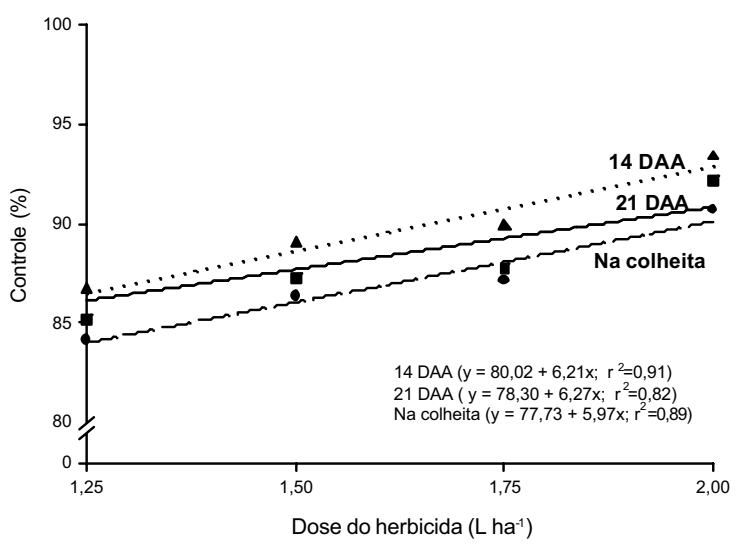

Figura 2 - Grau de controle de guanxuma (Sida rhombifolia L.) em função de doses do herbicida acifluorfen + bentazon, nas médias dos estádios de desenvolvimento da planta daninha, em três épocas de avaliação. Passo Fundo-RS, 1998/99. DAA = dias após aplicação.

herbicida, foi afetado pela época de aplicação (Tabela 3). Aos 14 DAA, obtiveram-se maiores graus de controle nas situações em que a aplicação do herbicida foi feita em plantas nos estádios de duas e quatro folhas; contudo, nas avaliações feitas aos 21 DAA e na colheita, o grau de controle diminuiu na aplicação realizada em plantas com duas folhas. Essa redução no controle deveu-se à ocorrência de novo fluxo de emergência de plantas daninhas após aplicação do herbicida. Considerando-se que o herbicida, nas doses utilizadas, possui somente ação em pós-emergência, plantas que emergiram posteriormente não foram atingidas.

Considerando todas as situações avaliadas, o grau de controle de picão-preto variou entre 78 e 99\% (Tabela 4 e Figura 3). O grau de controle de picão-preto propiciado pelo herbicida variou entre as épocas de aplicação, independentemente das doses utilizadas (Tabela 4). Na avaliação realizada aos 7 DAA, os maiores graus de controle ocorreram nas épocas 1 e 2, quando as plantas daninhas apresentavam duas e quatro folhas, respectivamente. $\mathrm{Na}$ época 1 , a exemplo do que foi observado para guanxuma, constatou-se diminuição no grau de controle à medida que a avaliação atrasou. Nas aplicações realizadas quando as plantas daninhas apresentavam seis folhas (épocas 3, 4 e 5), em geral foram obtidos controles inferiores, variáveis de 84 a $91 \%$.

Analisando as duas espécies-alvo do herbicida, constata-se que o melhor controle, considerando todo o ciclo, foi na aplicação em plantas daninhas com quatro folhas. A aplicação sobre plantas com duas folhas foi muito precoce, pois permitiu reinfestação posterior de plantas daninhas. Já a aplicação sobre plantas com seis folhas mostrou menor sensibilidade ao herbicida, especialmente no caso de guanxuma.

O efeito da época de aplicação do herbicida nos níveis de controle de guanxuma e picãopreto (Tabelas 3 e 4) influenciou o rendimento de grãos da cultura (Tabela 4). Obteve-se menor produtividade na época 1 , justamente aquela em que os graus de controle foram menores nas avaliações realizadas aos 21 DAA e na colheita da soja. Apesar de o controle obtido situar-se acima de 89\% (Figura 1 e Tabela 4), conforme foi observado para guanxuma e picão-preto aos 7 DAA, o novo fluxo de emergência de plantas daninhas que ocorreu refletiu negativamente no rendimento. Nesse sentido, Fleck et al. (2002a) salientam que a competição também pode ocorrer com plantas daninhas que escapam ao controle inicial, em decorrência da emergência mais tardia, o que influencia o rendimento final da cultura. No entanto, em muitas situações, as plantas daninhas podem emergir mais tarde do que a cultura, causando reduções de menor proporção no rendimento de grãos (Rizzardi et al., 2003b).

Planta Daninha, Viçosa-MG, v.22, n.1, p.117-125, 2004 
Tabela 3 - Grau de controle de guanxuma (Sida rhombifolia) em função de épocas de aplicação do herbicida acifluorfen + bentazon, na média de doses do produto. Passo Fundo-RS, 1998/99

\begin{tabular}{|c|c|c|c|c|}
\hline \multicolumn{2}{|c|}{ Épocas de aplicação do herbicida Doble } & \multicolumn{3}{|c|}{ Controle de guanxuma (\%) } \\
\hline Soja (folhas) & Plantas daninhas (folhas) & $14 \mathrm{DAA}^{1 /}$ & $21 \mathrm{DAA}$ & $\mathrm{Na}$ colheita \\
\hline Simples & 2 & $94 \mathrm{a}^{2 /}$ & $82 \mathrm{c}$ & $80 \mathrm{c}$ \\
\hline 1 trifoliolada & 4 & $96 \mathrm{a}$ & $96 \mathrm{a}$ & $95 \mathrm{a}$ \\
\hline 2 trifoliolada & 6 & $88 \mathrm{~b}$ & $88 \mathrm{~b}$ & $88 \mathrm{~b}$ \\
\hline 1 trifoliolada & 6 & $85 \mathrm{~b}$ & $87 \mathrm{~b}$ & $86 \mathrm{~b}$ \\
\hline Simples & 6 & $85 \mathrm{~b}$ & $86 \mathrm{~b}$ & $86 \mathrm{~b}$ \\
\hline \multicolumn{2}{|c|}{ Coeficiente de variação (\%) } & 4,37 & 4,46 & 4,97 \\
\hline \multicolumn{2}{|c|}{ F épocas de aplicação } & $28,29 *$ & $24,88^{*}$ & $18,51 *$ \\
\hline
\end{tabular}

${ }^{1 /}$ Dias após aplicação do herbicida; ${ }^{2 /}$ médias seguidas pela mesma letra, comparadas na coluna, não diferem pelo teste de Tukey a $5 \%$ de probabilidade; e * significativo a $5 \%$ de probabilidade.

Tabela 4 - Grau de controle de picão-preto (Bidens spp.) e rendimento de grãos de soja em função de épocas de aplicação do herbicida acifluorfen + bentazon, na média de doses do produto. Passo Fundo-RS, 1998/99

\begin{tabular}{|c|c|c|c|c|c|c|}
\hline \multicolumn{2}{|c|}{$\begin{array}{c}\text { Épocas de aplicação do herbicida } \\
\text { Doble }\end{array}$} & \multicolumn{4}{|c|}{ Controle de picão-preto (\%) } & \multirow{2}{*}{$\begin{array}{c}\text { Rendimento de grãos } \\
\left(\mathrm{kg} \mathrm{ha}^{-1}\right)\end{array}$} \\
\hline $\begin{array}{c}\text { Soja } \\
\text { (folhas) }\end{array}$ & $\begin{array}{l}\text { Plantas daninhas } \\
\text { (folhas) }\end{array}$ & $7 \mathrm{DAA}^{1 /}$ & 14 DAA & 21 DAA & Na colheita & \\
\hline Simples & 2 & $93 \mathrm{ab}^{2 /}$ & $95 \mathrm{ab}$ & $83 \mathrm{c}$ & $78 \mathrm{c}$ & $2241 \mathrm{~b}^{2 /}$ \\
\hline 1 trifoliolada & $\begin{array}{ll}3 \\
4\end{array}$ & $97 \mathrm{a}$ & $99 \mathrm{a}$ & $96 \mathrm{a}$ & $93 \mathrm{a}$ & $2568 \mathrm{a}$ \\
\hline 2 trifoliolada & 6. & $89 \mathrm{~b}$. & $89 \mathrm{ab}$ & $91 \mathrm{ab}$ & $88 \mathrm{ab}$ & $2523 \mathrm{a}$ \\
\hline 1 trifoliolada & $\begin{array}{ll}3 \\
6\end{array}$ & $89 \mathrm{~b}$ & $88 \mathrm{~b}$ & $87 \mathrm{bc}$ & $84 \mathrm{bc}$ & $2317 \mathrm{ab}$ \\
\hline Simples & 6 & $90 \mathrm{~b}$ & $89 \mathrm{ab}$ & $90 \mathrm{ab}$ & $86 \mathrm{~b}$ & $2560 \mathrm{a}$ \\
\hline \multicolumn{2}{|c|}{$\begin{array}{l}\text { Coeficiente de variação (\%) } \\
\text { F épocas de aplicação }\end{array}$} & $\begin{array}{c}5,08 \\
8,75^{*}\end{array}$ & $\begin{array}{c}4,47 \\
11,97 *\end{array}$ & $\begin{array}{c}4,67 \\
19,65^{*}\end{array}$ & $\begin{array}{c}6,72 \\
14,21\end{array}$ & $\begin{array}{c}9,76 \\
6,49^{*}\end{array}$ \\
\hline
\end{tabular}

${ }^{1 /}$ Dias após aplicação do herbicida; ${ }^{2 /}$ médias seguidas pela mesma letra, comparadas na coluna, não diferem pelo teste de Tukey a 5\% de probabilidade; e* significativo a $5 \%$ de probabilidade.

No caso das aplicações do herbicida em plantas daninhas no estádio de seis folhas, independentemente do estádio de crescimento da soja, tanto os graus de controle quanto os rendimentos de grãos foram equivalentes. Nessa situação particular, a diferença de até oito dias nas épocas de semeadura da soja não gerou vantagem competitiva sobre as plantas daninhas. Isso provavelmente se deve ao elevado nível de controle das plantas daninhas que o herbicida propiciou em praticamente todas as situações. Além disso, as populações de guanxuma e picão não resultaram em nivel elevado de interferência, mesmo no tratamento testemunha (redução de produtividade inferior a $20 \%$ ). Ao trabalharem com essas duas espécies de plantas daninhas, Rizzardi et al. (2003a) obtiveram perdas máximas de rendimento de grãos de soja de 58 e $14 \%$ para infestações de picão-preto e guanxuma, respectivamente. O reduzido nível de interferência pode ter ocorrido em razão da predominância de guanxuma na área, em relação ao picãopreto. A menor habilidade competitiva intrínseca da planta daninha, associada ao efeito supressor da soja, afetou o desenvolvimento da guanxuma, causando até mesmo a morte. Essa morte de plantas observada pode ser explicada pela capacidade de auto-ajuste que as plantas apresentam quando há restrição do ambiente no qual elas se encontram (Fleck et al., 2002b). 
A época de aplicação de herbicidas de pósemergência influencia o rendimento econômico (Berti et al., 1996). Segundo esses autores, com um tratamento precoce, a proporção de plantas daninhas controladas e as perdas econômicas que elas produziram foram pequenas, enquanto as plantas que emergiram após o tratamento ocasionaram maior impacto econômico. Por outro lado, assumindo um controle tardio, tanto a proporção de plantas daninhas que foram controladas quanto as perdas econômicas causadas foram maiores, enquanto as perdas devidas à emergência posterior das plantas daninhas foram pequenas. Em relação aos efeitos das doses dos herbicidas, tanto o controle de guanxuma quanto o de picão-preto aumentaram linearmente com o incremento daquela variável (Figuras 2 e 3 ).

O rendimento de grãos foi afetado pela dose do herbicida, independentemente da época de sua aplicação (Figura 4). A elevação na dose do herbicida ocasionou resposta linear positiva no rendimento de grãos, associado ao aumento do controle de plantas daninhas com o incremento na dose (Figuras 2 e 3), o que permitiu à cultura desenvolver-se plenamente sem interferência das plantas daninhas, resultando em produtividades similares à da testemunha sem plantas daninhas. Para cada redução de $0,25 \mathrm{~L} \mathrm{ha}^{-1}$ na dose do herbicida Doble, dentro da faixa avaliada, ocorreu redução próxima a $50 \mathrm{~kg} \mathrm{ha}^{-1}$ na produtividade

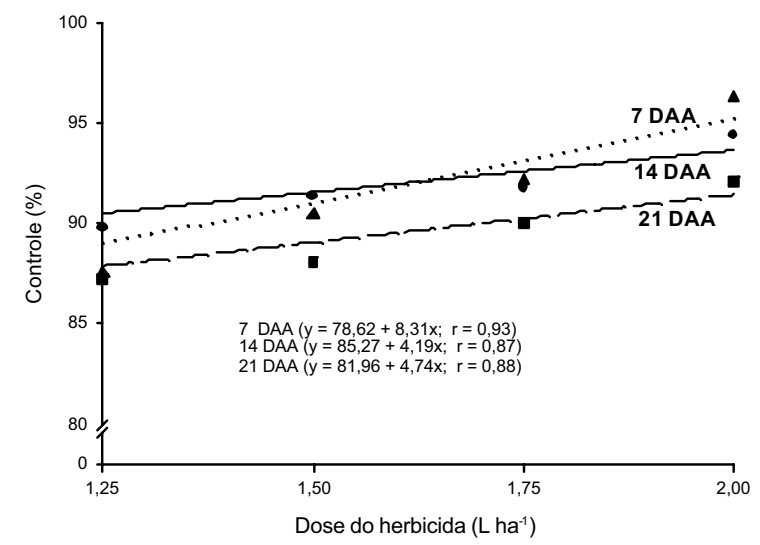

Figura 3 - Grau de controle de picão-preto (Bidens spp.) em função de doses do herbicida acifluorfen + bentazon, nas médias dos estádios de desenvolvimento da planta daninha, em três épocas de avaliação. Passo Fundo-RS, 1998/99. $\mathrm{DAA}=$ dias após aplicação. da soja. É importante salientar que, na ausência de controle, o rendimento foi, em média, 19,6\% inferior em relação ao da testemunha sem a presença de guanxuma e picãopreto.

Os resultados obtidos mostram que o incremento na dose do herbicida Doble resulta em retorno positivo em termos de produtividade da soja. Entretanto, para manejar uma população de plantas daninhas e maximizar o lucro, dois componentes distintos devem ser integrados: a densidade de dano de plantas daninhas que justifica a aplicação de um herbicida em pós-emergência na dose registrada (de rótulo) - aquela que normalmente propicia o maior grau de controle; e a dose ótima que é aplicada e que resulta na maximização do lucro. Para Dieleman et al. (1996), ambas as regras de decisão podem ser usadas no desenvolvimento de um programa de manejo integrado de plantas daninhas para se alcançar controle de custo eficiente.

A dose econômica ótima para controle de uma população mista de picão-preto e guanxuma, conforme foi obtido neste experimento, situa-se próximo a $75 \%$ da dose recomendada do herbicida - dose de rótulo (Figura 5). Portanto, ela é uma quarta parte inferior à dose que propiciou os maiores rendimentos de grãos (Figura 4). Esses resultados demonstram que os acréscimos em controle e

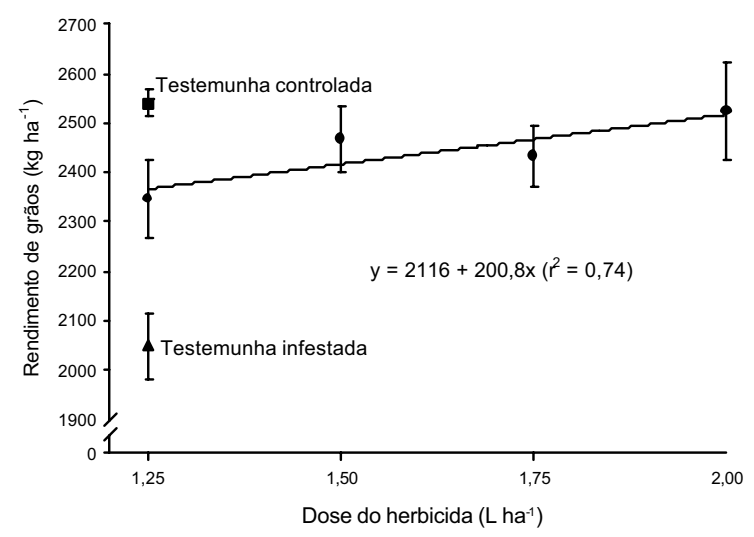

Figura 4 - Rendimento de grãos de soja em função de doses do herbicida acifluorfen + bentazon, nas médias de estádios das plantas daninhas guanxuma (Sida rhombifolia) e picãopreto (Bidens spp.). Passo Fundo-RS, 1998/99. (Barras verticais representam o erro-padrão da média).

Planta Daninha, Viçosa-MG, v.22, n.1, p.117-125, 2004 


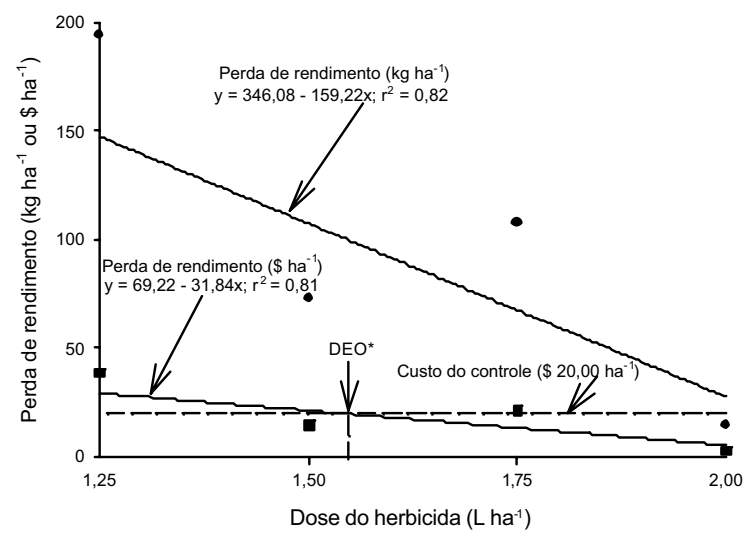

Figura 5 - Perda de rendimento de grãos de soja em função da dose do herbicida acifluorfen + bentazon e dose econômica ótima de controle de picão-preto (Bidens spp.) e guanxuma (Sida rhombifolia). Passo Fundo-RS, 1998/99. (*DEO = dose do herbicida na qual a perda monetária de rendimento se igualou ao custo de controle).

rendimento de grãos obtidos com as doses de 1,75 e 2,0 L ha-1 do herbicida Doble não foram suficientes para compensar o maior custo do controle. Possivelmente, com doses menores do que 1,75 e $2,0 \mathrm{~L} \mathrm{ha}^{-1}$ tenha ocorrido diminuição na habilidade competitiva das plantas daninhas que sobreviveram ao produto, a exemplo do relatado por Murphy \& Lindquist (2002). Para esses autores, o efeito dos herbicidas no crescimento da planta daninha varia com a dose de herbicida utilizada, e a supressão no crescimento da planta daninha afeta negativamente sua habilidade competitiva com a cultura.

De acordo com os resultados obtidos, a dose de rótulo de 2,0 $\mathrm{L} \mathrm{ha}^{-1}$ foi a que se mostrou biologicamente mais eficaz; já doses próximo a $75 \%$ da dose de rótulo foram as que compensaram economicamente a adoção do controle. Os resultados obtidos nesta pesquisa são importantes, uma vez que incorporam aspectos econômicos na tomada de decisão para controle de plantas daninhas na cultura da soja. Nesse contexto, a seleção da melhor opção de controle de plantas daninhas pode ser aperfeiçoada com o uso de sistemas de suporte de decisão, considerando-se os fatores que influenciam a eficácia do herbicida, como espécie daninha e estádio de desenvolvimento, e os aspectos econômicos do tratamento. A integração desses fatores permitirá o desenvolvimento de sistemas que minimizem os impactos ambientais dos herbicidas sem sacrificar a lucratividade da produção agrícola. Contudo, salienta-se que a infestação residual de plantas daninhas decorrente do uso de dose reduzida pode, potencialmente, causar aumento no banco de sementes em anos futuros.

\section{LITERATURA CITADA}

BERTI, A. et al. A new approach to determine when to control weeds. Weed Sci., v. 44, p. 496-503, 1996.

BOSNIC, A. C.; SWANTON, C. J. Economic decision rules for postemergence herbicide control of barnyardgrass (Echinochloa crus-galli) in corn (Zea mays). Weed Sci. v. 45, p. 557-563, 1997.

BOSTRÖM, U.; FOGELFORS, H. Response of weeds and crop yield to herbicide dose decision-support guidelines. Weed Sci., v. 50, p. 186-195, 2002.

DEFELICE, M. S. et al. Weed control in soybeans (Glycine max) with reduced rates of postemergence herbicides. Weed Sci., v. 37, p. 365-374, 1989.

DEVLIN, D. L.; LONG, J. H.; MADDUX, L. D. Using reduced rates of postemergence herbicides in soybeans (Glycine max). Weed Technol., v. 5, p. 834-840, 1991.

DIELEMAN, A. et al. Decision rules for postemergence control of pigweed (Amaranthus spp.) in soybean (Glycine max). Weed Sci., v. 44, p. 126-132, 1996.

\section{EMPRESA BRASILEIRA DE PESQUISA}

AGROPECUÁRIA - EMBRAPA. Centro Nacional de Pesquisa de Solos. Sistema brasileiro de classificação de solos. Brasília: 1999. $412 \mathrm{p}$.

FLECK, N.G. et al. Período crítico para controle de Brachiaria plantaginea em função de épocas de semeadura da soja após dessecação da cobertura vegetal. Planta Daninha, v. 20, p. 53-62, 2002a.

FLECK, N. G. et al. Densidade e características morfológicas de plantas de picão-preto na previsão de perdas de rendimento de grãos de soja por interferência. Planta Daninha, v. 20, p. 169-179, 2002 b.

JOHNSON, W. G. et al. Weed control with reduced rates of chlorimuron plus metribuzin and imazethapyr in no-till narrow-row soybean (Glycine max). Weed Technol., v. 12, v. 32-36, 1998

JORDAN, D. L. et al. Comparison of graminicides applied at equivalent costs in soybean (Glycine max). Weed Technol., v. 11, p. 804-809, 1997. 
KLINGAMAN, T. E.; KING, C. A.; OLIVER, L. R. Effect of application rate, weed species, and weed stage of growth on imazethapyr activity. Weed Sci., v. 40, p. 227-232, 1992.

MURPHY, C. A.; LINDQUIST, J. L. Growth response of velvetleaf to three postemergence herbicides. Weed Sci., v. 50, p. $364-369,2002$

RIZZARDI, M. A. et al. Perdas de rendimento de grãos de soja causadas por interferência de picão-preto e guanxuma. Ci. Rural, v. 33, 2003a.
RIZZARDI, M. A. et al. Ajuste de modelo para quantificar o efeito de plantas daninhas e época de semeadura no rendimento de soja. Pesq. Agropec. Bras., v. 38, p. 35-43, 2003 b.

SHAW, D. R. et al. Field validation of weed control recommendations from HERB and SWC herbicide recommendation models. Weed Technol., v. 12, p. 78-87, 1998.

WILKERSON, G. G. et al. HERB: decision model for postemergence weed control in soybean. Agron. J., v. 83, p. 413-417, 1991. 